\title{
Improved method for isolation and growth of Chlamydia trachomatis in McCoy cells treated with cycloheximide using polyethylene glycol
}

\author{
NOORIA RS MOHAMMED, IRENE B HILLARY \\ From the Department of Medical Microbiology, University College Dublin, Ireland
}

SUMMARY The sensitivity of non-replicating McCoy cells pretreated with polyethylene glycol for the isolation of Chlamydia trachomatis from clinical specimens and for the growth of a laboratory strain was compared with the sensitivity of untreated non-replicating cell cultures. The concentration of polyethylene glycol in different solutions and the time of addition to the cell culture medium were critical. A concentration of $35 \%$ polyethylene glycol in barbitone added to the cell culture growth medium either immediately before or immediately after infection with chlamydia increased the number of inclusions detected. The rate of isolation obtained from clinical specimens was also increased when cell cultures treated with polyethylene glycol were used.

Isolation of chlamydia is important both in routine diagnosis and in the epidemiological investigation of trachoma and non-specific genital infection. McCoy cells are now routinely used to isolate and grow chlamydia, and since the first description of the method in $1963^{1}$ several modifications of the technique have increased the sensitivity of cells to chlamydia and reduced the time needed for isolation. ${ }^{2}$ This investigation was undertaken with a view to developing a more sensitive technique for isolating Chlamydia trachomatis from clinical specimens to improve the diagnosis of chlamydial infection in patients in whom only a few elementary bodies are present.

\section{Material and methods}

\section{CLINICAL SPECIMENS}

Three hundred and fifty cervical and urethral specimens submitted for routine chlamydial culture to the Virus Reference Laboratory, University College Dublin, were included in this study. Swabs from patients were immersed in bijou bottles containing $2 \mathrm{ml}$ transport medium consisting of medium 199 supplemented with $10 \%$ fetal calf serum, $10 \%$ sorbitol, $200 \mu \mathrm{g}$ streptomycin $/ \mathrm{ml}$, and 100 units mycostatin/ml adjusted to $\mathrm{pH} 7 \cdot 2-7 \cdot 4$ with $4.4 \%$ sodium bicarbonate. All specimens were stored at $-70^{\circ} \mathrm{C}$ on arrival at the laboratory until tested.

Accepted for publication 3 May 1985
Treatment of McCoy cells

McCoy cell cultures treated with cycloheximide or were prepared as previously described. ${ }^{3}$ Solutions. containing a range (5-50\%) of concentrations of polyethylene glycol, molecular weight 4000 daltons (Sigma Chemical Co, England), were prepared in reagent grade water (Mill-Q System, Millipore Corporation, England); phosphate buffered saline (Flow Laboratories, Scotland); barbitone tablets as used in complement fixation tests, (Oxoid Ltd, England); and Hanks's balanced salt solution (Flow Laboratories, Scotland). Cell monolayers were treated with $0.2 \mathrm{ml}$ of a polyethylene glycol solution.

An inoculum of $0.2 \mathrm{ml}$ of a single dilution of the laboratory strain isolated from a cervical specimen $(78 \mathrm{M} / \mathrm{Cx})$ was added to each coverslip culture. After centrifugation at $2500 \mathrm{~g}$ for one hour the infected cell cultures were incubated at $36^{\circ} \mathrm{C}$ in an atmosphere of $5 \%$ carbon dioxide. After 48 hours of incu. bation the coverslips were stained with toluidine blue and examined for intracellular inclusions. ${ }^{3}$ All inoculations were performed in triplicate, and the $\Omega$ mean number of inclusions was calculated for each $N$ dilution. The optimal time for the addition of $\underset{\omega}{N}$ polyethylene glycol was determined by adding $0 \cdot 2$ O $\mathrm{ml}$ of $35 \%$ polyethylene glycol in barbitone to McCoy cultures at intervals before and after infec- $\frac{\overparen{\Phi}}{\Phi}$ tion, with an inoculum of $0.2 \mathrm{ml}$ of a single dilution $\stackrel{\infty}{+}$ of the laboratory strain $(78 \mathrm{M} / \mathrm{Cx})$. The clinical 0 specimens were treated in a similar manner-that is, $0.2 \mathrm{ml}$ inocula were used. 


\section{Results}

\section{CONCENTRATION OF POLYETHYLENE GLYCOL}

Fig. 1 shows the effect of the concentration of polyethylene glycol on inclusion counts using four diluents. As the concentration of polyethylene glycol was increased from $10-35 \%$ the number of inclusions detected increased accordingly, irrespective of the diluent used. The highest number of inclusions was found when cells were treated with $35 \%$ polyethylene glycol in barbitone. As concentrations of polyethylene glycol in excess of $35 \%$ were tested the number of inclusions detected decreased.

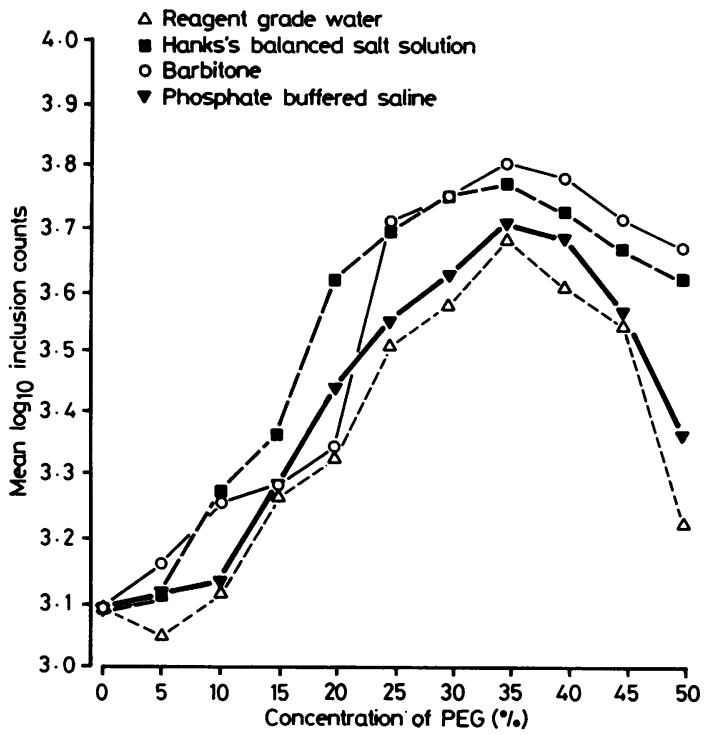

Fig. 1 Effect of increasing concentration of polyethylene glycol (PEG) in four diluents on inclusion counts of $(78 M / C x)$ strain in cell cultures.

\section{OPTIMUM TIME FOR THE ADDITION OF}

POLYETHYLENE GLYCOL

When polyethylene glycol was added before infection a slight decrease in inclusion counts was observed as the interval between treatment and infection was increased from 15 to 60 minutes (Fig. 2 ). With the addition of polyethylene glycol after infection a gradual decrease in inclusion counts was observed as the period between inoculation and addition was increased (Fig. 3). The highest number of inclusions was detected when the cell cultures were treated immediately after infection.

\section{ISOLATION OF C TRACHOMATIS USING CELL CULTURES TREATED WITH POLYETHYLENE GLYCOL AND NON-REPLICATING CELL CULTURES}

Each clinical specimen was inoculated into treated

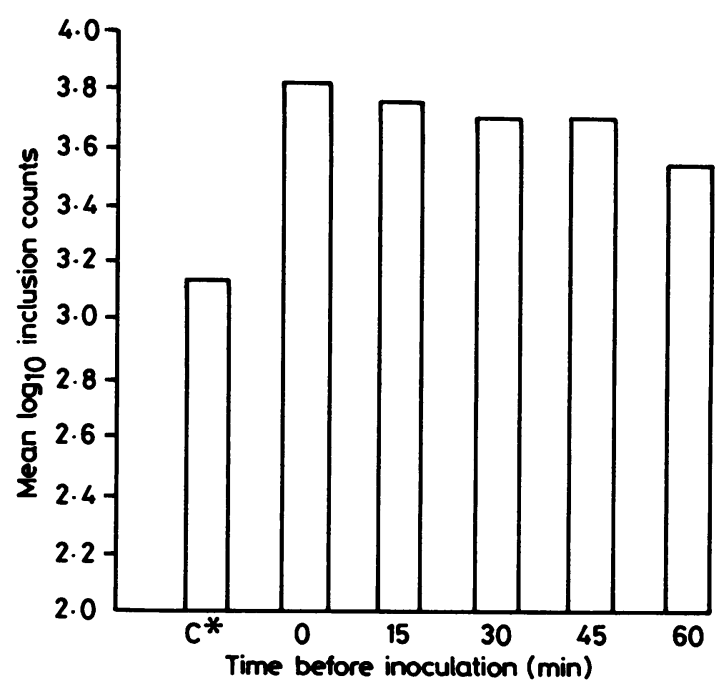

Fig. 2 Effect of addition of polyethylene glycol before inoculation with $(78 M / C x)$ strain. Control: no polyethylene glycol.

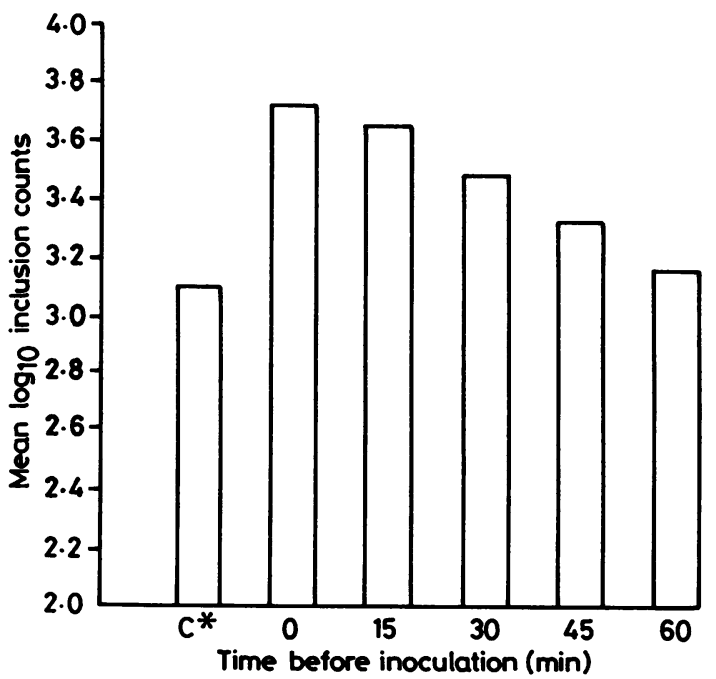

Fig. 3 Effect of addition of polyethylene glycol after inoculation with $(78 M / C x)$ strain. Control: no polyethylene glycol.

(35\% polyethylene glycol in barbitone) and nonreplicating McCoy cell cultures. Chlamydias were isolated from 57 of the 350 clinical specimens. Thirty nine specimens were positive in both cell culture systems, and 293 were negative in both cell culture systems. An additional 18 specimens were positive only in cell cultures treated with polyethylene glycol. The number of isolations of $C$ trachomatis in cell cultures treated with 
polyethylene glycol was significantly higher than in non-replicating cell cultures $\left(\chi^{2}=3.99, \mathrm{p}<0.05\right)$.

\section{Discussion}

The effect of different chemicals on the detection of chlamydial inclusions from strains in transit between laboratories or from clinical specimens has been reported previously. Kuo et al showed that treatment of HeLa-229 cells with polycations enhanced the infectivity of trachoma inclusion conjunctivitis organisms, whereas infectivity was reduced by treatment with polyanions. ${ }^{4}$ This shows the importance of overcoming the physicochemical forces that may interfere with the adsorption of chlamydia to the host cells. ${ }^{5}$ When cortisol was added to McCoy cell cultures at the time of infection with $C$ trachomatis the number of inclusions detected was increased 1.94-fold compared with non-replicating cells. ${ }^{6}$

In this study non-replicating monolayer cultures of McCoy cells treated with polyethylene glycol were found to be more sensitive than nonreplicating cultures for detecting inclusions from a laboratory strain of $C$ trachomatis (Figs. 1 and 2) and clinical specimens. When a range of concentrations of polyethylene glycol in different diluents was used for treating non-replicating McCoy cell cultures in conjunction with a constant inoculum of the laboratory strain the highest number of inclusions was found using $35 \%$ polyethylene glycol in barbitone (Fig. 1). The enhancing effect of polyethylene glycol on this culture system was evident over the range of concentrations examined and with each of the diluents used. The optimal time for treating the cell cultures with polyethylene glycol was either immediately before or immediately after inoculation. The number of isolations of $C$ trachomatis from clinical specimens in cell cultures treated with polyethylene glycol was significantly higher than in non-replicating cells; the rate of isolation was increased from $11 \%$ to $16 \%$. Becker et al showed that the adsorption of the elementary bodies to the cells is rapid, starting immediately after the addition of the particles to the host cells and reaching a maximum after three hours. ${ }^{7}$ In this study, however, the number of inclusions detected decreased when the time between inoculation and treatment of the cell cultures with polyethylene glycol increased.

The mechanism of action of polyethylene glycol is unclear. The increase in the number of inclusions detected in this study might have been due to an enhancement of adsorption or ingestion of the infective bodies by cells treated with polyethylene glycol or both. A further possibility is that polyethylene glycol affects the metabolism of McCoy cells in such a way as to alter their susceptibility to infection or that it induces McCoy cells to produce enzymes that promote chlamydial adsorption or ingestion, or both. Elucidation of the precise mechanism requires further study. In our opinion, the treatment of nonreplicating McCoy cell cultures with polyethylene glycol $(35 \%)$ in barbitone improves, in practical terms, the diagnosis of early or low grade chlamydial infection in patients whose specimens contain only a few $C$ trachomatis elementary bodies and so might otherwise be erroneously reported as negative.

We thank Seamus Dooley and Gerardine McQuoid for their help.

\section{References}

' Gordon FB, Magruder GB, Quan AL, Arm HG. Cell cultures fon detection of trachoma virus from experimental simian infe tions. Proc Soc Exp Biol Med 1963;112:236-42.

${ }^{2}$ Evans RT, Taylor-Robinson D. Comparison of various McC cell treatment procedures used for detection of Chlamydia trachomatis. J Clin Microbiol 1979;10:198-201.

${ }^{3}$ Mohammed NRS, Hillary IB. Detection of Chlamydia trachomatis inclusions in McCoy and HeLa-229 cells: an alternative staining technique using toluidine blue. J Clin Pathol 1984;37:682-5.

${ }^{4}$ Kuo CC, Wang SP, Grayston T. Effect of polycations, polyanions and neuraminidase on the infectivity of trachoma inclusion conjunctivitis and lymphogranuloma venereum organisms in HeLa cells. Infect Immun 1973;8:74-9.

${ }^{5}$ Ripa KT, Mardh RA. Cultivation of Chlamydia trachomatis in cycloheximide treated McCoy cells. J Clin Microbiol 1977;6:328-31.

${ }^{6}$ Bushell AC, Hobson D. Effect of cortisol on the growth of Chlamydia trachomatis in McCoy cells. Infect Immun 1978; 21:946-53.

' Becker Y, Hochberg E, Zakay-Rones Z. Interaction of trachoma elementary bodies with host cells. Isr J Med Sci 1969;5:121-4.

Requests for reprints to: Professor Irene B Hillary, Department of Medical Microbiology, University College or Dublin, Belfield, Dublin 4, Ireland. 